\title{
1000 Ventricular-vascular coupling is independently associated with exercise capacity in patients with ischemic cardiomyopathy: a cardiac multi-modality imaging study
}

\author{
Raymond C Wong, Carlos Dumont, Bethany A Austin, Deborah H Kwon, \\ Scott D Flamm, James D Thomas, Randall C Starling and Milind Y Desai*
}

Address: Cleveland Clinic, Cleveland, OH, USA

* Corresponding author

from I th Annual SCMR Scientific Sessions

Los Angeles, CA, USA. I-3 February 2008

Published: 22 October 2008

Journal of Cardiovascular Magnetic Resonance 2008, IO(Suppl I):AI25 doi:I0.II86/I532-429X-I0-SI-AI 25

This abstract is available from: http://jcmr-online.com/content/I0/SI/AI25

(c) 2008 Wong et al; licensee BioMed Central Ltd.

\section{Introduction}

Left ventricular (LV) systolic dysfunction due to ischemic cardiomyopathy (I-CMP) leads to reduced exercise capacity. Ventricular-vascular coupling (VVC), a ratio of effective arterial to LV elastance, represents forward flow efficiency of $\mathrm{LV}$, independent of mitral regurgitation.

\section{Purpose}

In I-CMP patients, we sought to a) assess relationship between resting VVC and maximum oxygen consumption corrected for peak heart rate $\left(\mathrm{MVO}_{2} / \mathrm{pHR}\right)$, an accurate measure of exercise capacity in patients on $\beta$-blockers, and b) compare value of VVC versus other determinants of exercise capacity.

\section{Methods}

43 patients with I-CMP (age $59 \pm 9$ years, $88 \%$ on $\beta$ blocker) underwent cardiopulmonary exercise testing, echocardiography and cardiac magnetic resonance (CMR, 1.5 T Siemens Scanners, Erlangen Germany) for cardiac transplant evaluation. $\mathrm{MVO}_{2} / \mathrm{pHR}$ and diastolic filling variables (echocardiography) were measured in a standard fashion. CMR LV indices [end-systolic (ESV), enddiastolic (EDV), stroke volume (SV), all in ml, and LVEF] were measured using the standard contiguous short-axis slices from apex to base, using the balanced steady state free precession cine sequence $(\mathrm{TE}=1.6 \mathrm{msec}, \mathrm{TR}=3.3$ msec, flip angle $=70^{\circ}$ and slice thickness $8-10 \mathrm{~mm}$, field of view varied from 228-330 in the x-direction and 260-
330 in the y-direction and matrix size varied from 140180 in the $\mathrm{x}$-direction and 256 in the y-direction, giving a spatial resolution of 1.5-2.1 mm (x-direction) by 1.1-1.4 $\mathrm{mm}$ (y-direction). For patients able to suspend respiration, breath hold duration was 10-15 sec, depending on the heart rate; otherwise, images were acquired using 3 signal averages. Subsequently, off-line analysis was performed using Argus analytical software (Siemens Medical Solutions, Erlangen, Germany) to assess LV volumes and LVEF, in a standard fashion. VVC was calculated as: [Effective arterial elastance (end systolic pressure $\div$ stroke volume index)/LV end-systolic elastance (end systolic pressure $\div$ LV systolic volume index)].

\section{Results}

Mean LVEF, ESV, EDV, and SV were $24 \pm 8 \%, 228 \pm 107$ $\mathrm{ml}, 297 \pm 111 \mathrm{ml}$, and $66 \pm 20 \mathrm{ml}$ respectively. Mean $\mathrm{MVO}_{2} / \mathrm{pHR}$ was $13 \pm 3 \mathrm{ml} /$ beat. Predictors of $\mathrm{MVO}_{2}$ are shown in Table 1. On stepwise regression, only VVC significantly predicted $\mathrm{MVO}_{2} / \mathrm{pHR}$.

\section{Conclusion}

In I-CMP patients with LV dysfunction, VVC predicts $\mathrm{MVO}_{2} / \mathrm{pHR}$ that can potentially be used as a potential therapeutic target. 
Table I: Univariate and multivariate predictors pf $\mathrm{MVO}_{2} /$ peak $\mathrm{HR}$.

\begin{tabular}{|c|c|c|c|}
\hline & \multicolumn{3}{|c|}{$\mathrm{MVO}_{2} /$ peak HR } \\
\hline & Correlation coefficient (rho) & $P$ value & Multivariate analysis $P$ value \\
\hline \multicolumn{4}{|l|}{ Clinical characteristics } \\
\hline Age & -0.006 & 0.9 & \\
\hline Gender & 0.1 & 0.5 & \\
\hline NYHA class & -0.14 & 0.4 & \\
\hline Baseline SBP & 0.22 & 0.16 & \\
\hline Baseline DBP & -0.02 & 0.9 & \\
\hline \multicolumn{4}{|c|}{ Echocardiographic and CMR features } \\
\hline$E \max$ & -0.39 & 0.009 & 0.1 \\
\hline E/A ratio & -0.23 & 0.1 & \\
\hline E wave deceleration time & 0.35 & 0.02 & 0.5 \\
\hline \multicolumn{4}{|l|}{ CMR features } \\
\hline LV end-systolic volume & -0.41 & 0.006 & 0.9 \\
\hline LV end-diastolic volume & -0.28 & 0.07 & \\
\hline Stroke volume & 0.14 & 0.3 & \\
\hline LV ejection fraction & 0.36 & 0.02 & 0.6 \\
\hline Ventricular vascular coupling & 0.45 & 0.002 & 0.001 \\
\hline $\mathrm{Ea}$ & -0.28 & 0.09 & \\
\hline Ees & 0.39 & 0.009 & \\
\hline
\end{tabular}

NYHA indicates New York Heart Association; SBP, systolic blood pressure; DBP, diastolic blood pressure; E max, mitral E wave velocity; LV, left ventricle; Ea, Arterial elastance; Ees, left ventricular systolic elastance.

Publish with Biomed Central and every scientist can read your work free of charge

"BioMed Central will be the most significant development for disseminating the results of biomedical research in our lifetime."

Sir Paul Nurse, Cancer Research UK

Your research papers will be:

- available free of charge to the entire biomedical community

- peer reviewed and published immediately upon acceptance

- cited in PubMed and archived on PubMed Central

- yours - you keep the copyright 